Jaurnal of Environmental Science, Computer Science and Engineering \& Technology

An International Peer Review E-3 Journal of Sciences and Technology

Available online at www.jecet.org

Section B: Computer Science

Research Article

\title{
Predicting customer complaints in Mobile Telecom Industry based on supervised machine learning
}

\author{
Hussain Ibrahim ${ }^{1}$ and Mazen Hakim ${ }^{2}$ \\ ${ }^{1}$ PHD student and ${ }^{2}$ Master Student, Varna Free University, Varna, Bulgaria
}

Received: 02 June 2021; Revised: 19 June 2021; Accepted: 30 June 2021

\begin{abstract}
The demand on telecom companies is still exponentially increasing on daily bases. In parallel, customer complaints from the services will have a similar curve. Most telecom companies rely on customer feedback to evaluate their network and services. In this thesis, we will take a Lebanese telecom company as a case study, and we will study the implementation of Machine Learning algorithms on it, using Artificial Neural Networks (ANN), comparing the feasibility of multiple optimizers and activation function to find the one that best suits our case. We are using a sample database of 10,000 mobile market subscribers with variables of gender, age, device manufacturer, service quality, and complaint status. We also propose the segmentedprediction model by window (interval time) and customer groups for better accuracy and practical usage. The customer group will have examined by gender, age, device manufacturer, and region area.
\end{abstract}

Keywords: Customer complaints, Machine Learning, prediction, Artificial Neural Networks, Mobile Telecom, network evaluation.

\section{INTRODUCTION}

Through decades customer feedback was the foundation stone in evaluating companies. For this reason, the call center, which is the intermediate department between the company and its client, has a crucial role in collecting the customers feedbacks, positive and negative ones, process and control them by automatic control system ${ }^{[1]}$. 
As technology evolves data throughput increases dramatically, but customer complaints are still inevitable. Table 1 below displays customer complaint reasons and propensity to complain according to service problem type.

Table 1: customer complaint reasons and propensity to complain according to service problem type.

\begin{tabular}{|l|c|l|c|c|c|c|c|}
\hline S.N0. & $\begin{array}{l}\text { Coverage } \\
\text { problem }\end{array}$ & $\begin{array}{l}\text { Difficulty } \\
\text { obtaining } \\
\text { information }\end{array}$ & $\begin{array}{l}\text { Incorrect } \\
\text { building }\end{array}$ & $\begin{array}{l}\text { Incorrect } \\
\text { charges }\end{array}$ & $\begin{array}{l}\text { Branch } \\
\text { of } \\
\text { contract }\end{array}$ & $\begin{array}{l}\text { Difficulty } \\
\text { unsubscribing }\end{array}$ & $\begin{array}{l}\text { Delayed } \\
\text { service }\end{array}$ \\
\hline N. users & 536 & 73 & 37 & 34 & 27 & 13 & 9 \\
\hline N. complains & 153 & 63 & 35 & 31 & 23 & 12 & 8 \\
\hline \% complains & $28.5 \%$ & $86.3 \%$ & $95.65 \%$ & $91.2 \%$ & $85.2 \%$ & $92.3 \%$ & $88.9 \%$ \\
\hline
\end{tabular}

Source: Garín-Muñoz Et. al., 2016. Note: $\mathbf{N}=729$ declared dissatisfaction at least once

It shows that there are various reasons that customers feel uncomfortable with including coverage problem, difficulty obtaining information, incorrect billing, incorrect charges, breach of contract, and delayed service.

The factor of our focus is the coverage factor. In telecommunications, the coverage is the geographic area where the base-station signal can cover. It depends on several factors, such as orography (Mountains) and buildings, and the type of technology used (example LTE). The ability of a mobile device to connect to a base station depends on the strength of its signal, and since buildings, especially the metals it contain, will attenuate signal, in addition that signal can't penetrate deeply underground, the signal may, sometimes, not have the efficient strength to have full coverage on specific areas.

Therefore, the coverage problem can be interpreted as a service quality problem; because most service quality problems are caused by bad coverage.

\section{MATERIALS}

2.1.Breif history about some solutions customer compliants: Customer's service quality experience is not easy to notice until customers actually complain. In order to resolve latent customer complaints, we may conclude that need to recognize and respond to customers who are experiencing bad service quality in advance before they complain.

It is important to have systems that identify the impending change in trend before it accelerates. These early warning systems are very important and will be useful in various scenarios like trading financial securities, predicting sales performance, analyzing the churn etc. ${ }^{[2]}$

Dr. Robert W. Proctor et a ${ }^{[3]}$ in year 2018 defined customer compliant as the client request or demand for an adjustment in a product or service.

The authors of ${ }^{[3]}$ built their definition according to many researches done previously. We will here mention the according to their chronological order. In 1977, Dickey and Talrzyk found that personal characteristics and internal influences have the largest effect on customer complaints. However, in 1980 Landon ${ }^{[4]}$ defined customer complaints as communicating something regarding a product or service from a company in a negative manner to either the firm manufacturer, or some other thirdparty organization entity, by the client. Jacoby, by his turn, said in $1981^{[5]}$ that many complaints are made by dissatisfied users of the product or service, and he proposed that major factors of these complaints are customer personality, attitude, motives, perceived value of time, information level, and socio-demographic characters. Additionally, Singh in $1996^{[6]}$ classified customer response to 3 kinds. First kind according to Singh was customers call the company directly to send their complaints. The 
second was boycotting the product and warning known people such as family, relatives, and friends. While the third kind is when a customer take a legal action against the company or even complaints it to the government directly, as illustrated in Figure 1.

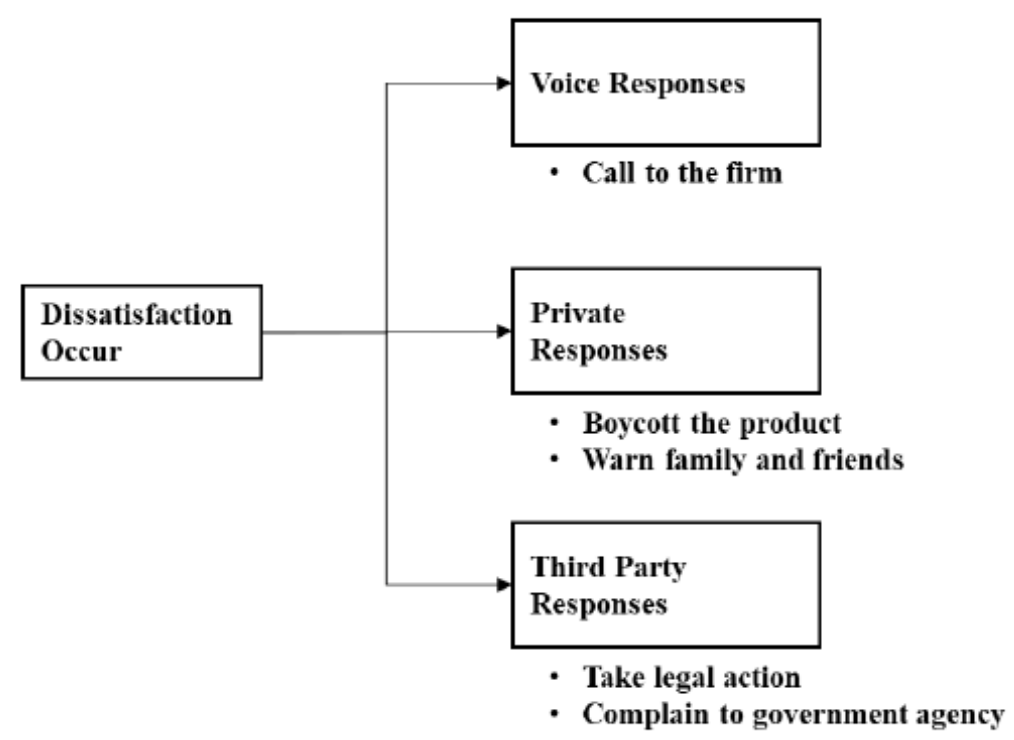

Figure 1: Customer Complaint Behavior Responses

According to exclaims, in year 2003, the characteristics that effect client complaints are demographic characteristics, customer experience, socio-cultural values, psychological, emotional and personality traits. Finally, the authors of ${ }^{[3]}$ mentioned the study done by Garín-Muñoz in year $2016^{[7]}$. GarínMuñoz made a study on customer complaints behavior in mobile telecom industry in Spain. The study was divide to 6 stages (Figure 2), where in stage 1 Garín-Muñoz collected data about telecom companies' customers and found that $28.5 \%$ of them experienced service problems. In the second stage the author of the study found that only $57.9 \%$ of these customers experiencing service problems complain, and the rest of the study stages resulted in that $94 \%$ of the complaining clients call the company directly.

If we make a small calculation, we can deduce that only $54.42 \%$ of clients experiencing service problems give their negative feedback to the firm, which means that $46.42 \%$ of those clients have no records in the company's database regarding a complaint. These results can be easy obtained by multiplying the percentage of customers complaining about a service $(57.9 \%)$ by those who have complained to the company directly, thus:

Customers complaining $\% *$ customers that sent their complaints

$$
\Rightarrow 57.9 \% * 94 \%=54.42 \%
$$

By subtracting this percentage from $100 \%$, the total clients facing service problems) we can find that $45.58 \%$ of clients don't complain to the company when they have a service problem, rather they may silently move to another company, and maybe warn other clients, consequently, spreading a negative atmosphere about the product and even the telecom company. The company may the touch that effect after the decreasing in its statistical numbers at late time. 


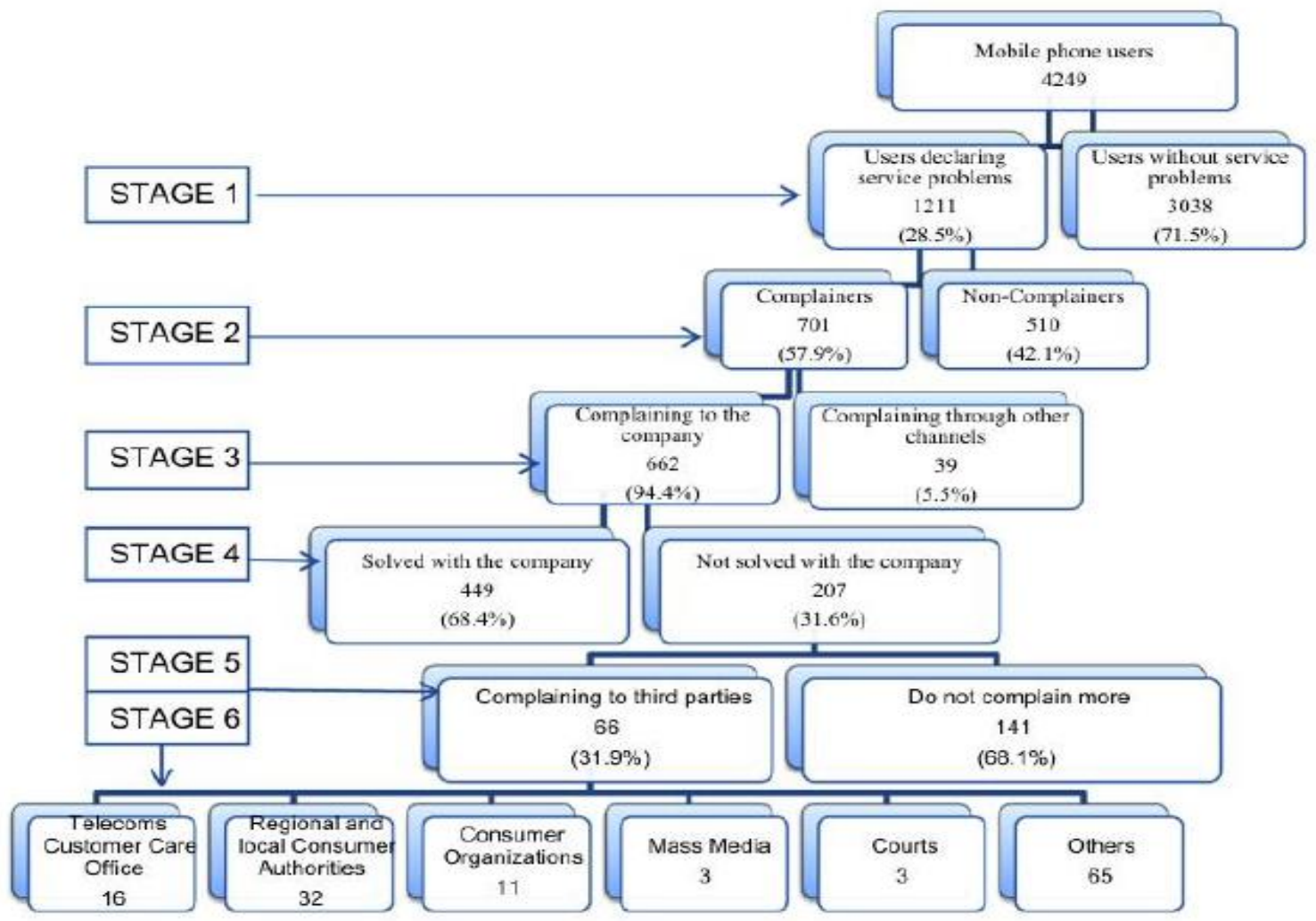

Figure 2: Customer complaint behavior analyses in telecom industry

If we calculate the percentage of clients complaining to the company we will find that $15.51 \%$ from the clients only call the company for a compliant, and we can get this by multiplying the percentage of clients experiencing service problem by the percentage of clients that complains in any way, multiplied by the percentage of clients that call the company to complain:

Clients experiencing service problem $\% *$ clients that complain $\% *$ clients that call $\%$

$$
\Rightarrow 28.5 \% * 57.9 \% * 94 \%=15.51 \%
$$

Then what about the rest $84.48 \%$ of clients? Are they satisfied with the service? On the other hand, they are planning to move soon.

These studies and many others are done to know how a client may behave when a service or a product is not as far as his/her aspirations are, but mostly those studies relied on surveys and interview data, and lack the collection of all client data in one model. Moreover, they lack the ability to predict whether the client is, or may; complain about a service or product.

Here comes the power of Machine Learning (ML) modeling that this article focus on. In this article, we propose a model that uses multiple attributes collected from a Lebanese telecom company database related to customers' data to analyze and predict customer complaints using ML Artificial Neural Networks (ANNs). We did a comparison between multiple activation functions, also between loss functions, with different learning rates to find the best and most accurate model to predict the rest of clients if they should complain or no. 
2.2.Research overview and objective: As we illustrated in the previous section $45.58 \%$ of clients that are unsatisfied with the service doesn't complain to the company, while in total only $15.51 \%$ of clients have a negative feedback to the company, thus according to the study of Garín-Muñoz the company needs a way to predict the rest $84.49 \%$ of the clients satisfaction.

In this paper we will propose an Artificial Neural Network (ANN) model that uses Logistic Regression (LR) to predict if a client has a problem in the service or no. Through the project we will discuss and compare between multiple activation functions and multiple parameters optimizers to choose the best fit with the highest accuracy.We then use the Recurrent Neural Network (RNN) to evaluate our company services (mainly network coverage) with time, and predict if it is going to be better or worse.

\section{MODELING}

3.1. What is Logistic Regression (LR): Logistic regression was proposed in the late 1960s and early 1970s (Cabrera, 1994), and it became routinely available in statistical packages in the early $1980 \mathrm{~s}^{[8]}$.

According to GARY M. INGERSOLL ${ }^{[9]}$ the mathematical concept underlying logistic regression is the logarithm - the natural logarithm of the coefficients. The simplest example of an entry is derived from a $2 \times 2$ unforeseen table. Consider an example where the distribution of a dichotomous outcome variable (an urban schoolchild for whom correctional reading is recommended) is combined with a dichotomous (sex) predictor variable. Typical data are presented in Table 2. The independence test can be applied using the chi-square. This results in ${ }^{2}(1)=3.43$.

Table 2: sample data for gender and recommendation for remedial reading instructions

\begin{tabular}{|c|c|c|c|}
\hline \multirow{2}{*}{ Remedial reading instructions } & \multicolumn{2}{|c|}{ Gender } & \multirow{2}{*}{ Total } \\
\cline { 2 - 3 } & Boys & Girls & \\
\hline Recommended (coded as 1) & $\mathbf{7 3}$ & $\mathbf{1 5}$ & $\mathbf{8 8}$ \\
\hline Recommended (coded as 0) & $\mathbf{2 3}$ & $\mathbf{1 1}$ & $\mathbf{3 4}$ \\
\hline Total & $\mathbf{9 6}$ & $\mathbf{2 6}$ & $\mathbf{1 2 2}$ \\
\hline
\end{tabular}

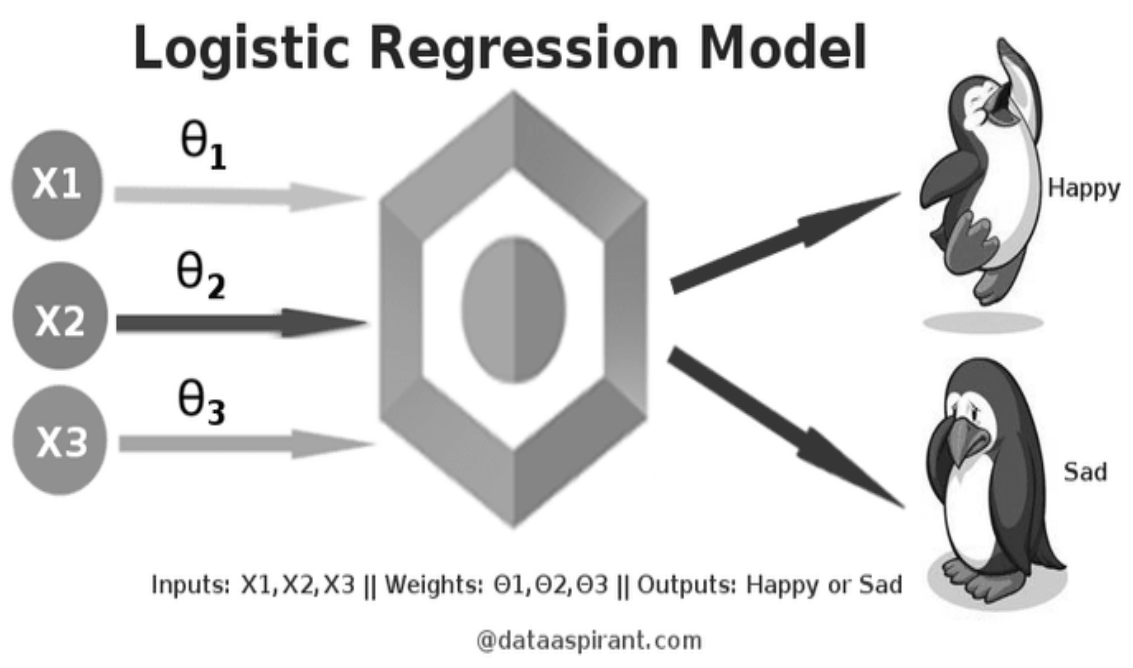

Figure 3: Logistic Regression Model logic 
Alternatively, it may be better to assess the likelihood that the boy should advised to improve reading instruction compared to the girl's factor. The result is an odds ratio of 2.33, indicating that boys are advising to be 2.33 times more likely than girls in reading correction the classes. The ratio of transactions is deriving from two coefficients (73/23 for boys and 15/11 for girls); its natural logarithm [that is, $\ln (2,33)$ ] is a logarithm equal to 0.85 . The value of 0.85 would be the regression coefficient for the gender prediction if a logistic regression has used to model the two scores for the correction recommendation because it is sex-related.

In general, logistic regression is suitable for describing and testing hypotheses about the relationships between a categorical outcome variable and one or more categorical or continuous prediction variables.

3.2. Activation functions used: Activation functions have a major role in Artificial Neural Network (ANN) architecture. They give it the non-linear properties giving it the ability to learn complex representations. At the beginning of ANN exploration Sigmoid was the most used function as an activation function. However, with years of practice in several fields, Sigmoid point of weakness in its small derivative that leads to vanishing gradient problem was accepted, and some other activation functions has explored and used instead, such as softmax, and ReLU. ReLU, for example, has a derivative of one for every positive input ${ }^{[10]}$.

3.2.1. Sigmoid: Sigmoid activation function translates the input range from $(-\infty ;+\infty)$ to the range in $[0 ; 1]$. It is non-linear by nature and has a smooth derivative as shown in figure 5 . Due to the output range of the sigmoid $[0 ; 1]$ the output of each unit is also squashed causing the gradient to vanish especially in a deep network ${ }^{[10] .}$

$$
\sigma(x)=\frac{1}{1+e^{-x}}
$$

Figure 4: Sigmoid equation

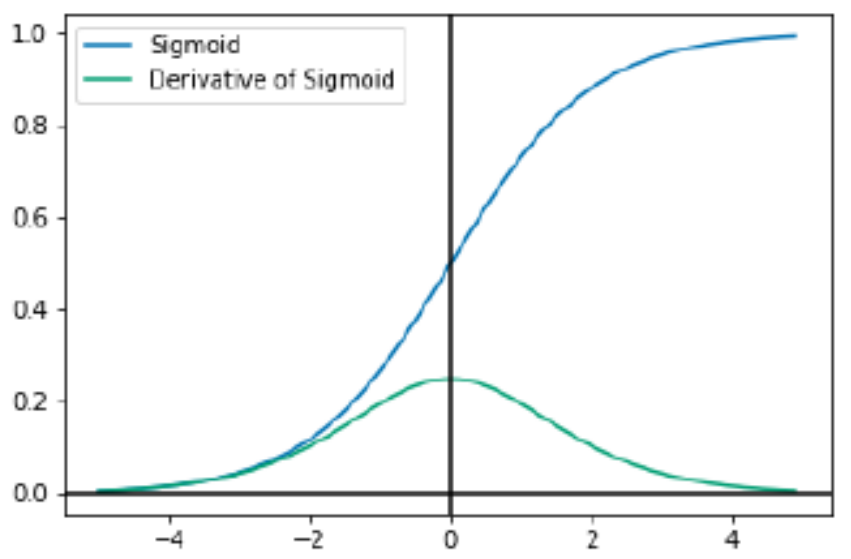

Figure 5: Plot of the sigmoid function and its derivative

3.2.2. ReLU: ReLU is a linear activation function that sets any negative number to zero while leaving any positive number as it is. This give ReLU the advantage of simplicity, but at the same time transforming all negative numbers to zero is a downside for it, since it causes every negative unit to output zero. This problem is called "dying ReLU". It is a special case of vanishing gradient problem. So once the neuron gets negative it is unlikely for it to recover ${ }^{[10] .}$ 


$$
\operatorname{ReLU}(x)=\max (0, x)
$$

Figure 6: ReLU equation

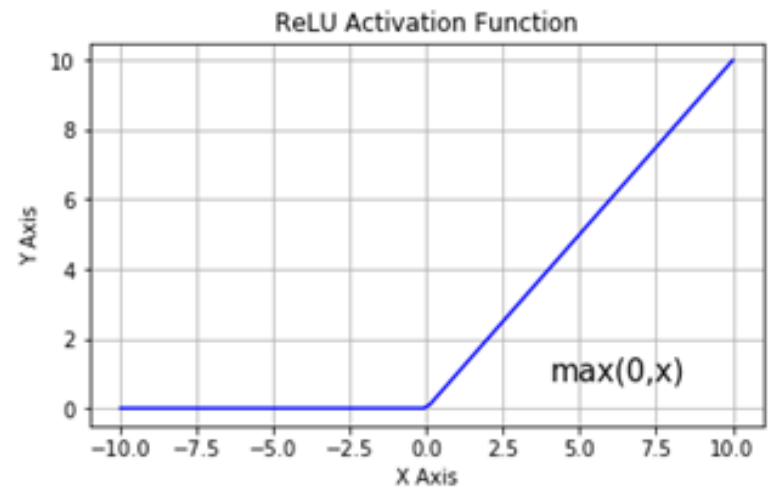

Figure 7: ReLU function graph

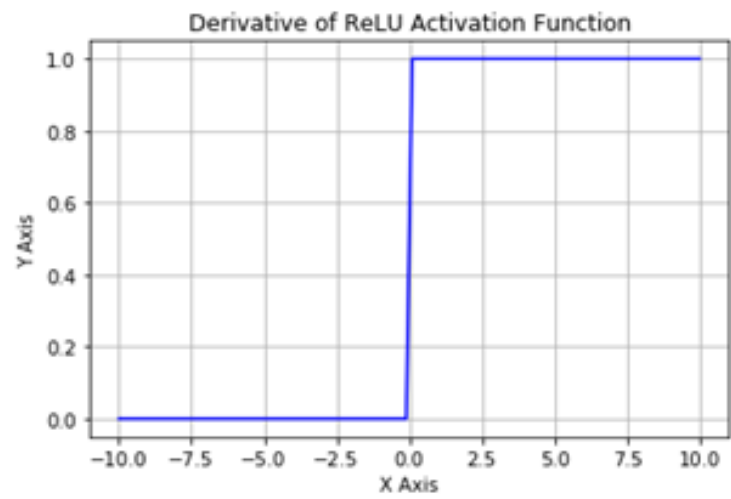

Figure 8: ReLU derivate graph

3.2.3. Softmax: Mainly Softmax activation function has used in the output layer (last layer) of neural network whenever classification has needed. The form of a Softmax unit is given in the below the example is for a K-class classification problem, and each Softmax unit i produces the probability that the input belongs to class i. For example, for the MNIST classification problem (classification of digits) $\mathrm{K}=10$ since there are 10 possible digit choices ${ }^{[11]}$.

$$
\sigma(z)_{j}=\frac{e^{z_{j}}}{\sum_{i=1}^{K} e^{z_{i}}}
$$

Figure 9: Softmax equation

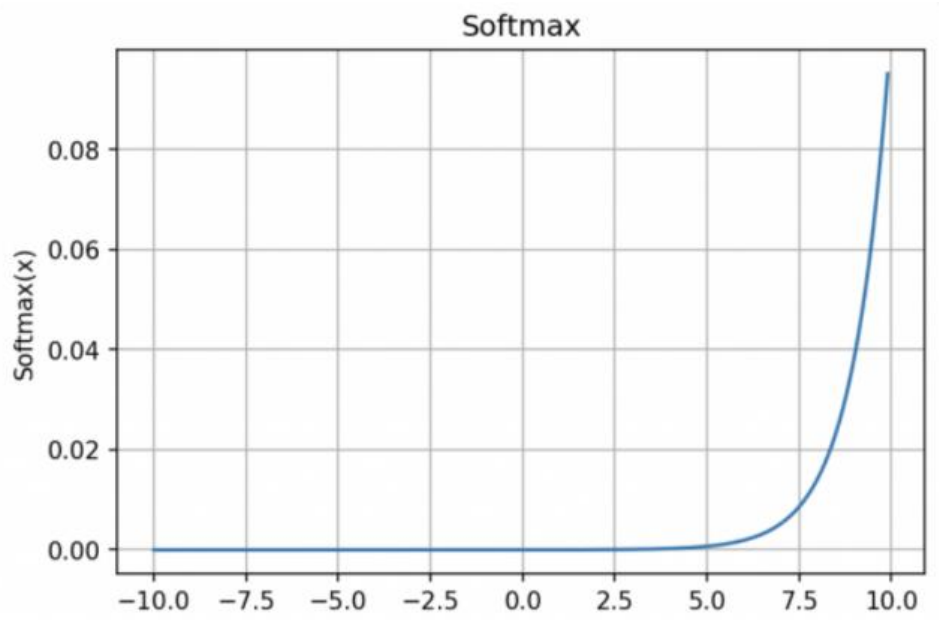

Figure 10: Softmax function graph

\section{METHODOLOGY}

4.1. Dataset sample: For its power we mainly used ReLU as the activation function in the input and hidden layers, and Softmax at the output layer. A comparison between different optimizers with different learning rate was done to find the optimizer that is most suitable for our project. 
Table 3: A comparison between different optimizers with different learning rate

\begin{tabular}{|c|c|c|c|c|}
\hline \multirow[b]{2}{*}{ Different parameters } & \multicolumn{4}{|c|}{ Device model } \\
\hline & $\begin{array}{l}\text { Apple A1901/ } \\
\text { apple iPhone X }\end{array}$ & $\begin{array}{c}\text { Samsung } \\
\text { SM- } \\
\text { J200H/ } \\
\text { Samsung } \\
\text { GalaxyJ2 }\end{array}$ & $\begin{array}{c}\text { Samsung } \\
\text { SM-G920F/ } \\
\text { Samsung } \\
\text { Galaxy S6 }\end{array}$ & $\begin{array}{c}\text { Samsung } \\
\text { SM-G610FDS/ } \\
\text { Samsung } \\
\text { Galaxy J }\end{array}$ \\
\hline Area & BEIRUT & BEIRUT & BEIRUT & BEIRUT \\
\hline PSTN ID & 360 & 72 & 517 & 518 \\
\hline Age & B & B & $\mathrm{C}$ & A \\
\hline title & MS. & Dr. & Eng. & Mr. \\
\hline Local call & Yes & Yes & No & Yes \\
\hline Roaming call & No & No & Yes & No \\
\hline $\begin{array}{l}\text { AVG voice } \\
\text { Call duration/ cycle }\end{array}$ & 72 & 14 & 14 & 104 \\
\hline $\begin{array}{l}\text { AVG data Call } \\
\text { duration/ cycle }\end{array}$ & 180 & 36 & 258 & 260 \\
\hline Nbr Voice Call/cycle & 12 & 12 & 24 & 36 \\
\hline Nbr data Call/cycle & 30 & 30 & 18 & 18 \\
\hline Service type & HS4 & HS2 & HS3 & HS4 \\
\hline Speed & $4 \mathrm{G}$ & $4 \mathrm{G}$ & $4 \mathrm{G}$ & $3 \mathrm{G}$ \\
\hline $\begin{array}{l}\text { Network Coverage } \\
\text { Traffic failure }\end{array}$ & 1 & 0 & 0 & 0 \\
\hline $\begin{array}{l}\text { Data Consumption } \\
\text { failure }\end{array}$ & 0 & 0 & 0 & 0 \\
\hline
\end{tabular}

4.2. RMSprop learning rate $=0.001$

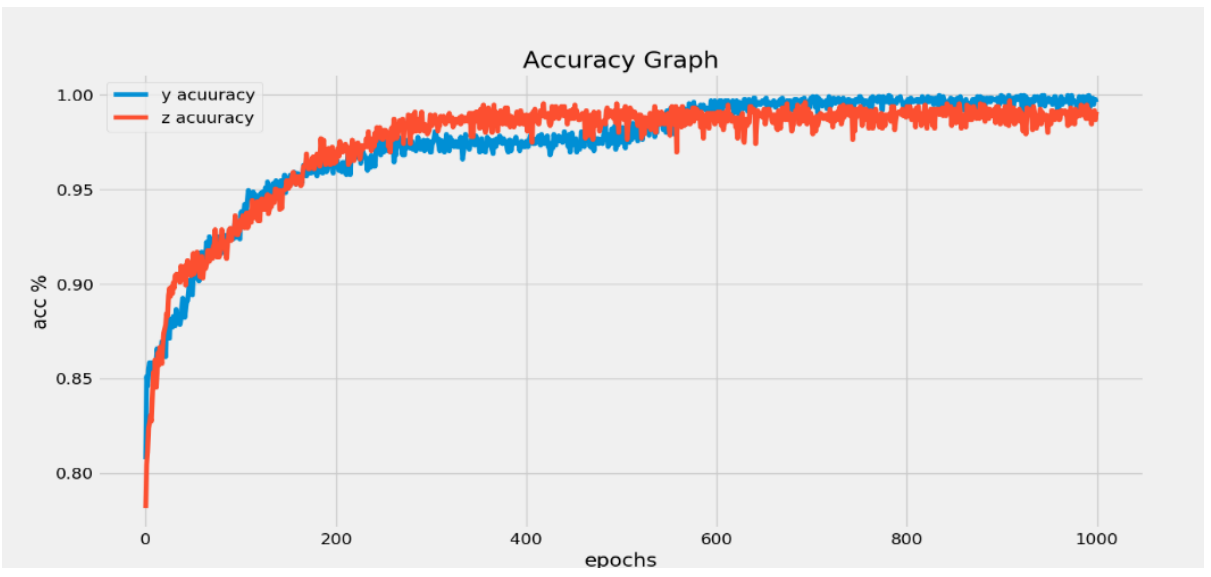

Figure 11: Accuracy graph RMSprop 
4.3. RMSprop Learning rate $=\mathbf{0} .0001$

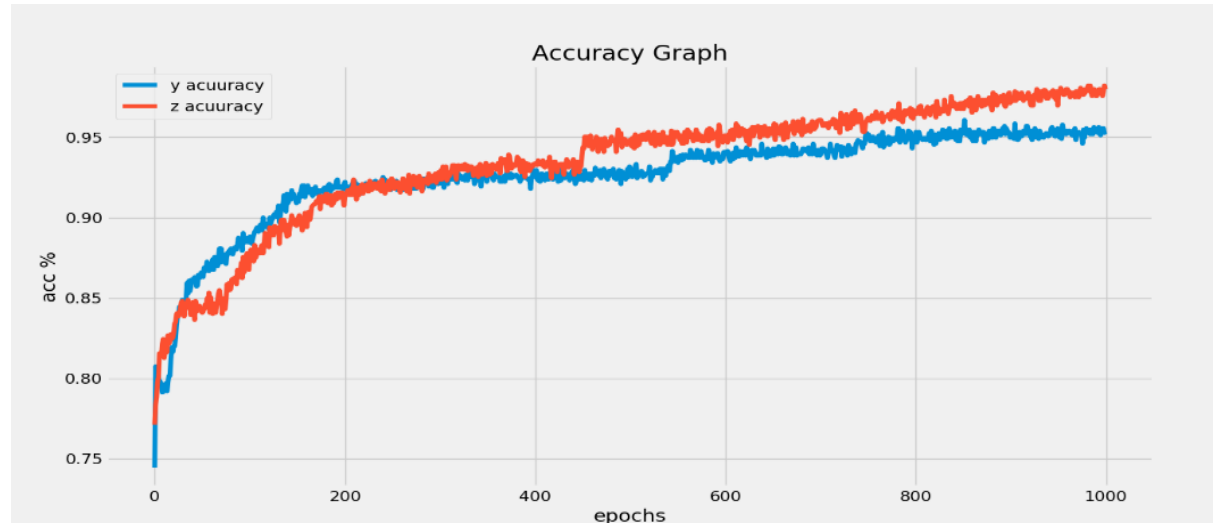

Figure 12: Accuracy graph RMSprop

\subsection{SGD learning rate $=0.01$}

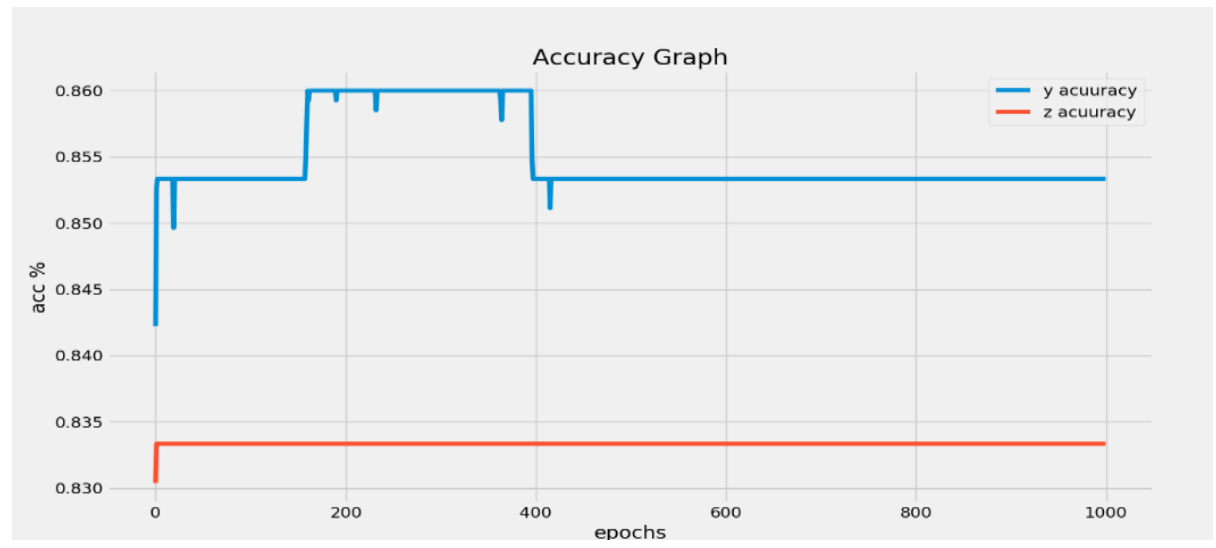

Figure 12: Accuracy graph SGD

We can notice over fitting of the neural network here where the curve gives a straight line indicating that the accuracy is standing on about 0.866 and 0.84 for ' $y$ accuracy' and on about 0.834 for ' $z$ accuracy'.

\subsection{SGD learning rate $=\mathbf{0} .0001$}

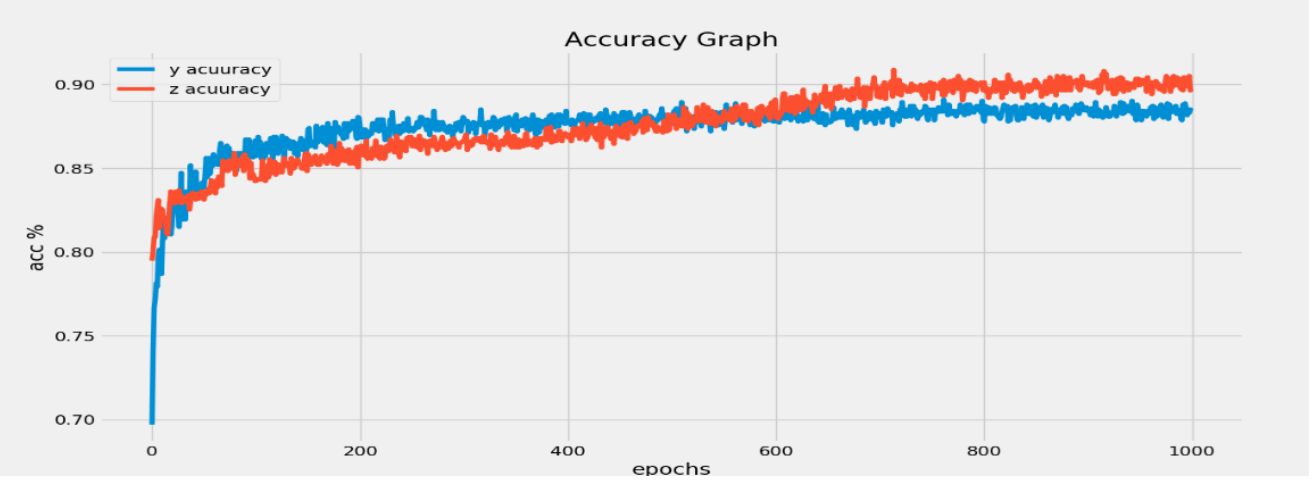

Figure 13: Accuracy graph SGD 
This curve does not indicate the over fitting of the network, although it does not give so accurate results as RMSprop because of the over fitting on the trained set.

\section{CONCLUSION}

In the mobile telecommunication technologies and data sciences, the mobile operators can collect various data from customers' service experience. This thesis utilized the advantage of those datasets and proposed a novel methodology. This research shows that customer complaints can be predicted using machine learning techniques. Combinational dataset from a real industry mobile operator were used as learning input data. We propose a new research method for customer complaints prediction with an accuracy of over $92 \%$. Although this accuracy is good, improvement in it can be achieved with larger training datasets and maybe a better combination between activation functions and their learning rate.

Nearly all measures revealed that, although ANN is the most complex algorithm, ANN had the best prediction performance.

In the coming work we will use segmented prediction and measure the influence of the demographic variables and device manufacturers on customer complaints. The measure the relation between gender and age with device manufacturers and what significant influences on predicting customer complaints.

\section{REFERENCES}

1. Jie Lu, Liyun Liu, Yun Nie and Hao Huang X. "Exploration to Improve the Service Quality and Reduce the Power Customer Complaints" State Grid Jiangxi Electric Power Research Institute, Jiangxi Nanchang 330096

2. L. Suresh, J. Simha, and V. Rajappa, "Analysis and prediction server with column store database, A case study in telecom churn" Published in TENCON 2009 - 2009 IEEE Region 10 Conference, DOI: 10.1109/TENCON. 2009. 5395982.

3. C. Choi, "Predicting Customer Complaints in Mobile Telecom Industry Using Machine Learning Algorithms". Available ProQuest, 2018, 1-76, 8, [Online]. Available: https://docs.lib.purdue.edu/dissertations/AAI10791168.

4. E. Laird Landon, Jr., University of Houston, "The Direction of Consumer Complaint Research," in NA - Advances in Consumer Research Volume 07, eds. Jerry C. Olson, Ann Abor, MI: Association for Consumer Research, Pages 335-338. [Online]. Available: https://www.acrwebsite.org.

5. J. JACCARD and J. Jacoby, "The sources, meaning, and validity of consumer complaint behavior: A psychological analysis," J. Retail., 1981, 57, 4-24. [Online]. Available: https://nyuscholars.nyu.edu/en/publications/the-sources-meaning-and-validity-of-consumercomplaint-behavior-a.

6. J. Singh and R. Wilkes, "When Consumers Complain: A Path Analysis of the Key Antecedents of Consumer Complaint Response Estimates," Journal of the academy of marketing sciences, 1996, 24, 350-365, Doi: 10.1177/0092070396244006.

7. T. Garín-Muñoz, T. Pérez-Amaral, C. Gijón, and R. López, "Consumer complaint behaviour in telecommunications: The case of mobile phone users in Spain," Telecommun. Policy, 2016, 40, 8, 804-820, Aug. 2016, Doi: 10.1016/j.telpol.2015.05.002.

8. A. Cabrera, "Logistic Regression Analysis in Higher Education: An Applied Perspective" in Higher Education: Handbook of Theory and Research, 1994, (225-256), 10, 225-256. 
9. Chao-Ying Joanne Peng, Kuk Lida Lee and Gary M. Ingersoll, “An Introduction to Logistic Regression Analysis and Reporting", Indiana University Bloomington, J. Educ. Res., 2002, 96, 1, 3-14, Sep. 2002, Doi: 10.1080/ 00220670209598786.

10. A. D. Rasamoelina, F. Adjailia, and P. Sinčák, "A Review of Activation Function for Artificial Neural Network," in 2020 IEEE 18th World Symposium on Applied Machine Intelligence and Informatics (SAMI), Jan. 2020, Doi: 10.1109/SAMI48414.2020.9108717.

11. A. Kagalkar and S. Raghuram, "CORDIC Based Implementation of the Softmax Activation Function," in 2020 24th International Symposium on VLSI Design and Test (VDAT), Bhubaneswar, India, Jul. 2020, pp. 1-4, Doi: 10.1109/VDAT50263.2020.9190498.

\section{* Corresponding Author: Hussain Ibrahim}

PHD student Varna Free University, Varna, Bulgaria

Online date of publication: 05.07 .2021 